\title{
Organizational Culture Key Role in a Successful Change Management Process
}

\author{
COVIC, D. \& Planinic, I.
}

Abstract: For a successful adaptation, it is necessary to change the organizational culture, i.e. to create your own, original and desired organizational culture. In today's rapidly evolving world, many companies are trying to gain a competitive advantage based on a cheaper product. Other companies copy other people's successes, products or just cosmetically change someone else's service and present it as their own. In this way, some companies may be even more successful with a product or service than those who originally designed them. However, one thing that cannot be copied is organizational culture. The work will be focused, but not limited, on the micro environment and its impact, because previous research and work in this field are mostly general and provide a broader picture of the situation in this field, which is very difficult to frame through a regional approach and apply to business of similar companies in Bosnia and Herzegovina. On the other hand, our country is not an island, and in a global environment, it is certain that the impact from the world market will positively or negatively spill over to regional markets. The goal is to be prepared to respond to certain impacts with adequate business solutions.

Key words: organizational culture, business system, competitive advantage, change management
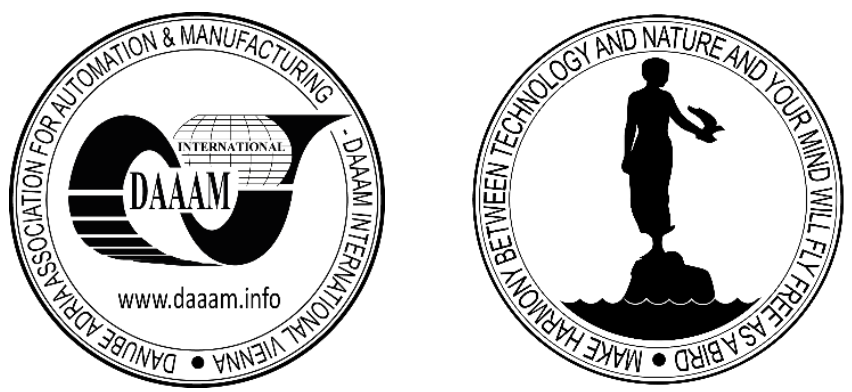

Authors' data: Univ.Prof.Dr.Sc. Covic, D[ragan]*; PhD student. Planinic, I[gor]*, * University of Mostar, Faculty of Mechanical Engineering, Computing and Electrical Engineering, 88000 Mostar, Bosnia and Herzegovina, dragan.covic@ fsre.sum.ba, igor.planinic@tel.net.ba

This Publication has to be referred as: Covic, D[ragan] \& Planinic, I[gor] (2020). Organizational Culture Key Role in a Successful Change Management Process, Chapter 10 in DAAAM International Scientific Book 2020, pp.131-142, B. Katalinic (Ed.), Published by DAAAM International, ISBN 978-3-902734-27-3, ISSN 17269687, Vienna, Austria

DOI: 10.2507/daaam.scibook.2020.10 


\section{Introduction}

Present times have been marked by strong development of capital, new products and technologies that produce those products, all in light of the constant breaking down of borders and the rapidly advancing globalization. Arising is a new world without borders, connected by Internet and other communications technologies, enabling the flow and immediate availability of information and making it possible to work from any place on the planet.

To to be able to operate in this globalized market, every business system must own a ,product/service“ that will maintain its competitive advantage over the competition all the while meeting the needs of its customers. Each business system must be innovative and unique if it wants to survive in the business environment, which is why acquiring new knowledge becomes an important process for its organisational structure. They become learning organisations, they gather and adopt valuable information, thus creating added value through innovation.

It is critical that they understand that every part of product innovation brings them competitive advantage. Most of the organizations that are not self-sufficient or do not produce their own finished products have to meet the expectations of their customers in order to avoid the change on their final products that the customer would like to do (Polasek \& Simon, 2018).

Throughout his development, man has always used some form of organisation or has belonged to one to help him reach his goals and fulfil his needs. In the past, these needs were mostly material, however, they are now social, cultural, sports, emotional and many other needs. If it was not for the organisation he was part of, he would probably not be able to fulfil these needs. In other words, it is through organisation that he reached his goals in a more effective, faster, rational and economic manner.

Success and survival of a business system is nowadays based on organisational culture as a key advantage. Why? Because it is beliefs that business systems have that make them successful. Putting into action what is identified as important is a foundation of good entrepreneurship, and development in general. Organisational culture is a basic pattern of employee behaviour, their beliefs and values. As it involves also learning or expanding the existing knowledge, both collective and individual, and transferring patterns of behaviour over time, one may easily conclude that the organisational culture of a business system is pretty stable and cannot change rapidly. It involves also the rules of employee conduct as well as interactions with one another.

The ability of a business system to survive is largely related to the ability to adapt to a changing environment but also to making new technologies and processes because if we can make something that others cannot make, or make the same in a more economic and cost-effective way, this in itself is a great competitive advantage. A successful organisation is equally focused on the necessary change and the ways of making this change. Therefore, the change management system is an essential part of implementing organisational change and changing the organisation. (Alfirevic et al, 2014). 


\section{Organisational culture of business systems}

There have been numerous attempts at defining organisational culture in scientific papers that address this topic. One of the earlier definitions was provided by Silversweig and Allen who refer to organisational culture as 'a set of expected behaviours that are generally supported within the group' (Silversweig \& Allen, 1976). One of the most detailed definitions of organisational culture may have been given by Schein (Schein, 1992) in his book Organizational Culture and Leadership, stating that „Organizational culture is the pattern of basic assumptions that a group has invented, or discovered in learning to cope with its problems of external adaptation and internal integration, and that have worked well enough to be considered valid and, therefore, to be taught to new members as the correct way to perceive, think, and feel in relation to those problems".

An adequate and strong culture is one of the basic preconditions for implementing a certain strategy and it therefore appears as sort of a substitute to a number of rules, regulations and other organisational mechanisms that govern mutual relations and behaviour of members and organisational units (Zugaj et al, 1999). We would like to highlight the following definition of organisational culture as it stresses its importance for a business system: „Culture is a relatively lasting and specific system of behaviour patterns, values, beliefs, norms and customs that determine the organisational behaviour and opinion and drives all individual and group activities. It is important to underline the relative continuity and stability of organisational culture. It reflects a specific model of behaviour and lifestyle of the organisation and groups within it" (Zugaj et al, 2004).

It is rather difficult to make an objective assessment of an organisation's culture as it is largely based on things that we take as premise or which are based on each individual's assumptions about it. This has led to many psychologists who determined that each individual's interpretation of the reality of organisational culture may be categorised, each category serving as a framework for different assumptions which may eventually be used to express a certain culture, which basically represents values and interpretations through different symbols (Mitrof, 1983). Perhaps the best known and probably most widely used model of archetype test is Jungian model (Jung, 1923) which was used as a basis for the recently developed model of organisation-related values or the competitive model of organisational effectiveness. The model was developed from empirical evidence by Quinn and Rohrbaugh (1981) when they analysed the values that educated individuals in an organisation considered desirable in the context of organisational effectiveness.

We have made reference here to the Jungian and competitive models to demonstrate that they both provide values, assumptions and opinions which form an organisation, thus creating a model or basis for organisational culture typology, which differentiates between 4 types of culture (Cameron \& Freeman, 1991). 


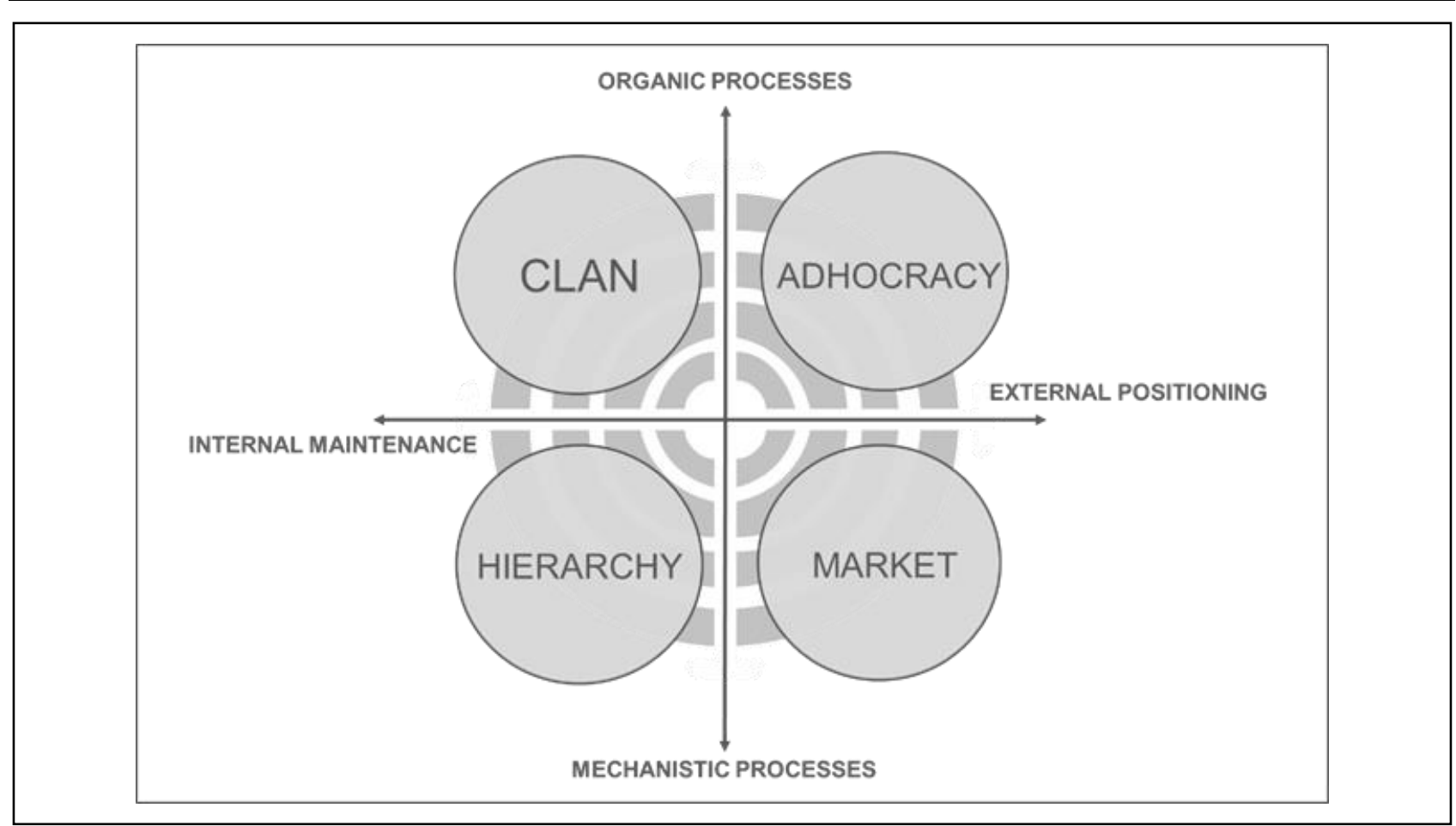

Fig 1. Types of the culture of organization

In their research paper, Kim S. Cameron and Sara J. Freeman published a case study of the relationship between congruence, strength and type of organisational culture and effectiveness in 334 higher education institutions in the United States that was rated based on three criteria. The results of research were in support of their argument that it is the culture that is assessed rather than the attributes of an organisation, which goes to show different possibilities of using the above model but also emphasise the significance of competitive advantage of the organisational culture.

Research into organisational culture in Bosnia and Herzegovina is very rare with some research conducted in the Republic of Croatia that demonstrate its diversity and its extensive relevance, especially in the process of change in business systems. Because, in the same way that the organisational culture can have a positive effect, it too can have a negative effect, especially in the countries in transition which include Bosnia and Herzegovina, In this context, we would like to point to a problem that may arise in public systems which see frequent change of management failing to implement desired goals but which also may arise due to poor results of business. In addition, a more significant factor is the employees, the human resources. They must strive to be open-minded and motivated to embrace the change taking place, otherwise they can pose the greatest barrier to change.

\section{Knowledge, innovation and creativity of a learning organisation}

Organisations are becoming more innovative by the day. This is reflected not only on new products or technologies as the most common subjects of innovation but also on innovations in organisational setup or interactions within the organisation and its culture or in the field of marketing or human resources. Innovations are critical to the progress of any business system, regardless of its size in terms of the number of people 
its employs or the number of branch offices it has. In the circumstances of the new century and exceptional advances made in technology, innovation may be perceived as a very significant competitive advantage of an organisation.

The significance of innovation, creativity and entrepreneurial spirit is frequently addressed by different bodies of the European Union, one of them being the European Economic and Social Committee (EESC). In its 2019 publication (EESC, 2019) it calls for enabling and encouraging policies that stimulate creativity, innovation, ongoing learning, agility and entrepreneurial spirit throughout society. They emphasise that entrepreneurship in its broadest sense is the ability of individual to turn ideas into actions. It implies creativity, innovation and risk-taking as well the project planning and project management ability in reaching desired goals.

In doing business, organisations are paying more and more attention to creativity. Successful organisations will appreciate their creative employees. They ought to particularly be appreciated by their managers. In today's business world, it is almost impossible to find a business system or even department or workplace that does not require creativity to get to better and more effective solutions. Thus, by encouraging creativity it is possible to make a difference between an average and successful business system. A research into business creativity was conducted by Amabile [Amabile, 1996) among 238 people working on creative projects in 7 organisations.

The research resulted in six myths about creativity in organisations:

- Creativity comes from creative types

- Money is a creative motivator

- Time pressure fuels creativity

- Fear forces breakthroughs

- Competition beats collaboration

- A streamlined organisation is a creative organisation

The author further explained each of the myths and proved that they were either false or true. In debunking the first myth for example, the author proved that anyone with normal intelligence is capable of doing some degree of creative work. It is up to the managers to recognise this and encourage creativity in every department, even in finances. Further, the widespread belief that competition fosters innovation or that time pressure fuels creativity is simply wrong because time pressure stifles creativity since people cannot deeply engage with the problem or manage to keep their focus long enough.

In order to maximise their creative process, business systems use the function of research and development. One of the finer illustrations of that process was given by Cook (Cook, 2002), where inputs such as ideas, people and finances, with the addition of creativity, produce outputs in the form of innovation, market share growth and return on investment (ROI). 


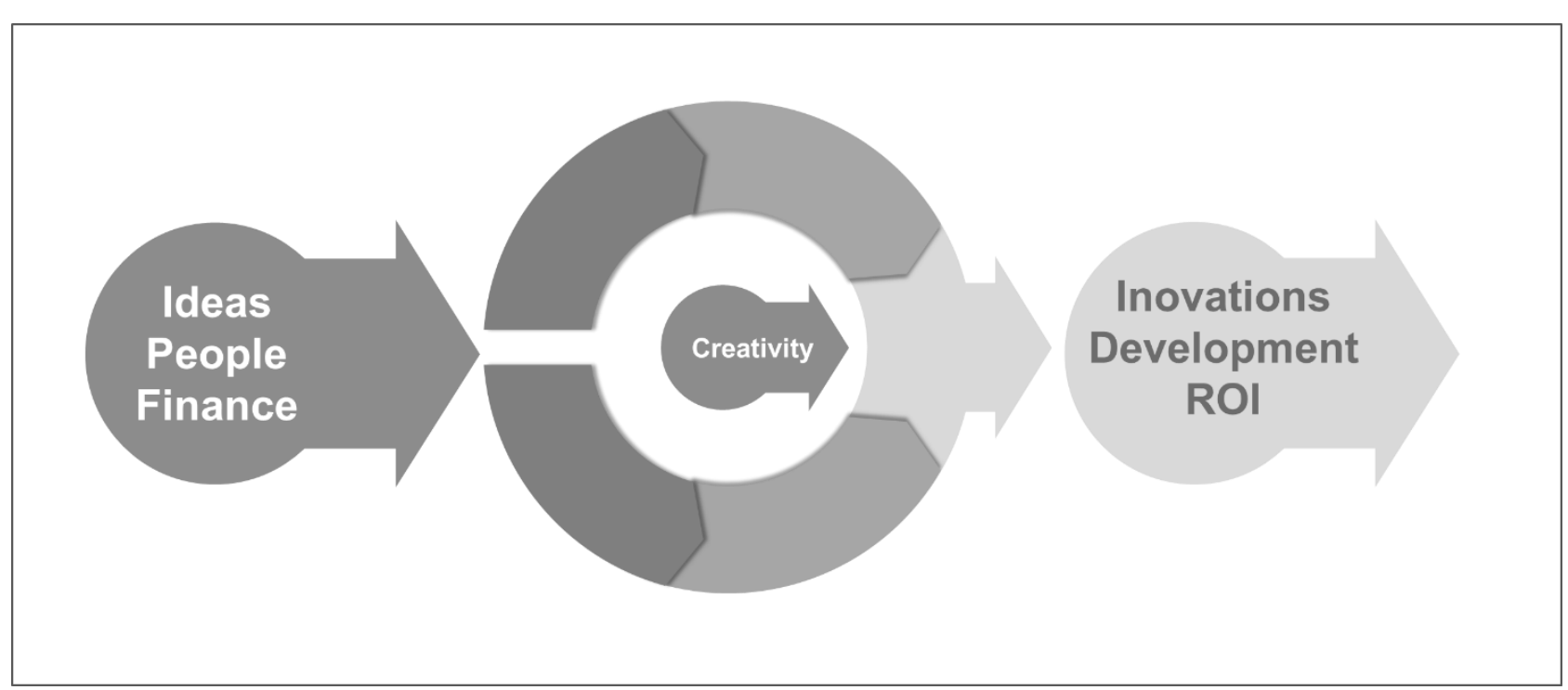

Fig. 2. Creativity process, prepared by the authors in accordance with Cook, P. (2002), Best Practice Creativity, Gower Publishing Limited, Hampshire, England, p. 62

A learning organisation must in any event manage its knowledge. Those two concepts are closely related. "New knowledge is based on the existing personal beliefs combined with information which is based on data. Data may be defined as unprocessed facts, such as numbers ad letters which are put into a context to create information. Combining the information with the existing beliefs, skills and individual perception creates knowledge. Therefore, data, information and knowledge are separate entities" (Mazur et al, 2014).

Learning is a process and an ability of adopting new knowledge or improving and building on the prior knowledge. A learning organisation provides support, encourages both individual and collective learning and fosters sharing of information and experience. This creates a very flexible organisation where new ideas are born and working practices are changed to align the organisation with the external environment. There are certain studies which suggest that organisational learning and organisational knowledge are a forerunner of innovation. Given that an organisation is composed of individuals, it follows that any innovation must begin with employees interacting with one another and sharing their knowledge with the organisation; this continued collaboration and discussion generate new knowledge. Therefore, one may conclude that a learning organisation perceives the process of learning as a constant and creative activity and thus strives to reach its goals and create its own future.

There is a misconception that an organisation cannot learn because it is not a living organism. If we take a look at all the approaches to a learning organisation, it may be concluded that an organisation learns in order to best adapt to its environment, enhance its ability to change and develop collective and individual learning with the end result of doing business in a more effective and efficient way. A learning organisation cannot be said to exist in a particular state or that it is taken out of or taken from the state. It is a time process just like the changes that keep coming from the environment. In the search for ongoing learning we come across a spirit of the learning organisation. People who find personal fulfilment in such environment feel satisfaction in belonging to such 
business system and in turn perform with satisfaction. Time is not an enemy to such business system but rather a partner and an ally (Covic, 2004). Such organisation draws its competitive edge from the intellectual capital as it is composed of people and not norms or procedures.

\section{CD - organisation}

CD-organisation is a system of a unity in action that allows efficient organizational learning by transferring the knowledge inside the CD structures of the organizations. This mutual trust built within the structure creates a basis for building an intelligent organisation. A business system is perceived as a living organism full of creativity and initiative and based on a positive synergy of networked individuals demonstrating dominant capabilities and efficiency.

A key challenge for these $\mathrm{CD}$ structures is the ability to adapt rapidly to changes in the environment; in other words, the possibility for an inefficient part of the CD structure to quickly intensify its activity and performance or be replaced with another.

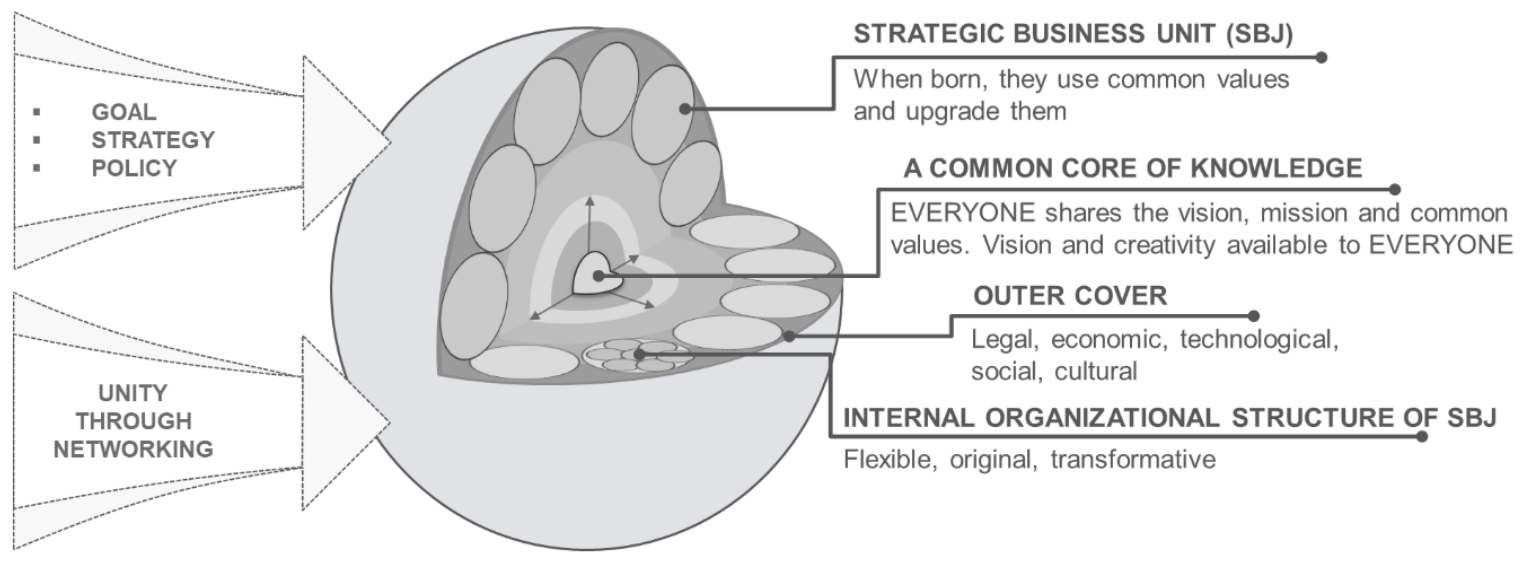

Fig. 3. CD model of organisation

Diversification of the CD organization is in its mutual internal dependences as a precondition for the stability of the business system. This high-level interdependence ensures a quality life cycle of a business system/organisation. Further, this interdependence gives a sense of trust and commitment between the organisation, tasks and employees (human resources - individuals).

As a living organism, a CD organisation, is made up of numerous, often very different structures, working in a constant interaction with one another. This brings different values in the organisation which are needed to reach a common goal. Flow of ideas and knowledge between a basic business unit of a business system is a process which does not enable us to determine the beginning or ending of a CD organization of a business system. An emphasis on horizontal in a CD organization guarantees a more developed and better used present knowledge, which forces the slower ones to 
act. By increased speed and different directions for transformation of knowledge, we ensure that knowledge is transferred from an individual level to the level of a business system. By mixing cultures, preferences and experiences, it opens numerous new possibilities for a man as a base of the $\mathrm{CD}$ organization of a business system (Covic, 2012).

\section{Change management in business systems}

The concept of organisational change may be looked at as a complex entity, comprising different factors of the organisation. In the new world of business, every organisation or a business system is required to be flexible and take the changes occurring in its micro or macro environment not only as a threat but also as an opportunity for further growth. How this business system will act with regards to its environment or in the interaction with it is largely dependent on the system itself, which is why it has to monitor the said changes. As a consequence, the new circumstances demand that managers be focused more on finding ways to manage change.

These processes has significantly changed from the former traditional idea of a formulated process of organisational change. It is not before the beginning of the 21st century that more attention has been paid to change as a significant factor in the life of a business system. If they want to survive in the turbulent business environment, today's business systems must be able to make a quality and adequate response to changes that the competition has in store but also to all the other changes in its micro or macro environment. Therefore, business systems should start abandoning traditional ways of change management and ensure that their development is based on own enhanced creativity, knowledge and innovation. Any change carries with it elements of the unknown, therefore, every change will bring about a degree on uncertainty and risk. But with good assessment and distinction between the changes we have planned and those coming from the environment, we make the process manageable. Change management means management of complexity, planning, evaluation and strategy implementation, which results from the fact that changes are one of the major constants recorded in history (Senge, 1990).
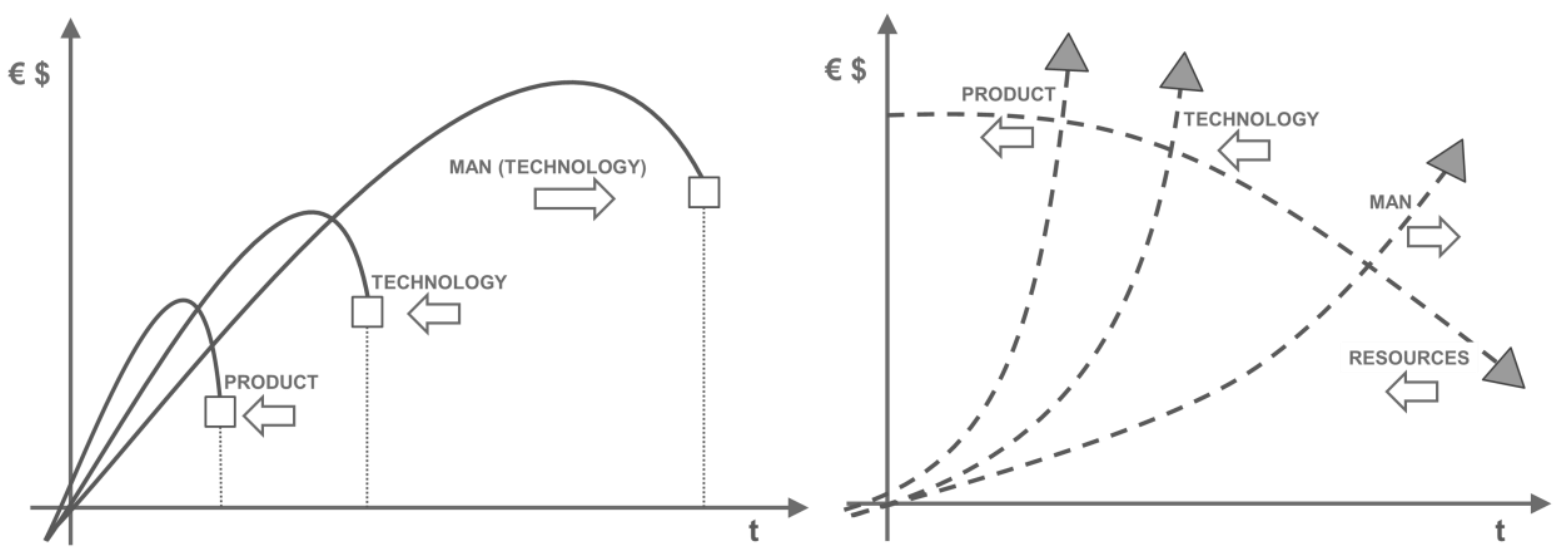

Fig. 4. Dynamics of change within business systems 
Due to intense competition on the market, organisational changes are focused on future. Modern trends cause the changes to be more complex and dynamic and harder to anticipate, giving rise to situations that the management finds hard to tackle. This assumes that the organisational change is actually a process of moving the organisation from its present state to a desired future state in order to increase as much as possible its efficiency and gain competitive advantage.

Speaking globally, managers in our micro environment often look for reasons why some business systems last longer on the market while others die early on their business journey or soon afterwards. Research into this topic was conducted both in Europe and the United States (Mazur \& Porass, 1994); (de Geus, 2002); (Stadler, 2007). They showed that the sensitivity of those business systems to their environment was critical to its adaptation and quick response to constant changes. Of the research into the change management process in business systems in our micro environment, I would like to point to that of Aleksic (Aleksic, 2009).

Like the authors before her, the fundamental question was how business systems last through the years, in this case the entire century. The research included a study of 58 enterprises in the Republic of Croatia with a century long tradition of doing business, analysing what it is that made them last so long and to what extent did organisational changes, and the management of organisational changes, contribute to those companies overcoming the change and survive.

The results showed to be similar to those in the rest of the world, demonstrating the business systems in the Republic of Croatia have come to appreciate the significance of the change management system and the importance of nurturing it through the years. The business systems which were successful in managing their life cycle curves were also successful in managing the change and creating and maintaining their competitive advantage through the years.

\section{Organisational culture as a key element of a successful change management system}

The goal that any business system should work towards is having an organisational culture that is well received by its employees, the one that ensures harmonisation between the goals of the system and its employees. In such an environment, individuals would pass their experiences onto the group, thus building a stable system and a stable business.

Further, adopting the organisational culture would enable employees to pursue the fulfilment of one of the basic human needs according to Maslow (Maslow, 1954), the need for self-actualisation. The said need is at the top of the pyramid and refers to pursuit of full realisation of one's potential, development and ultimate experience. 


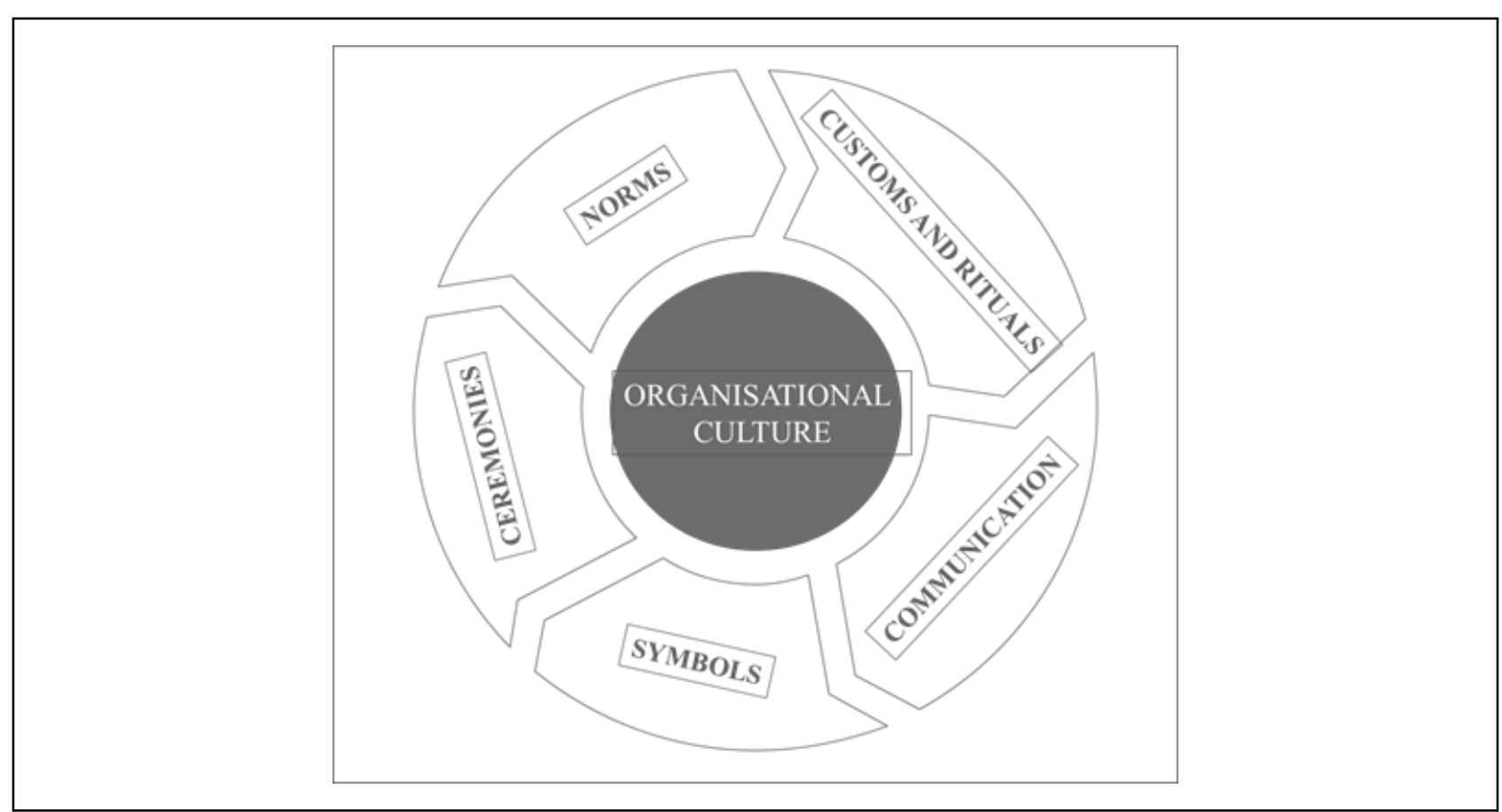

Fig 5. Values of organisational culture

Drawing on the selected values of organisational culture as shown above, it is possible to change employees' reflections, influence their beliefs and views, their perceptions of the organisation, their behaviours and, ultimately, the change. In fact, the main possibility or one of the main possibilities that organisational culture can offer is that we are able to manage our organisation because the above values can be changed and aligned with strategy. This leads to a conclusion that building a strong organisational culture can help us reduce employees' resistance to change and build a positive attitude to it. The proof of this argument was offered by Rahman and associates (Rahman, 2004) in a study of 258 manufacturing companies in Malaysia, showing a strong association between organisational culture and an attitude towards organisational change..

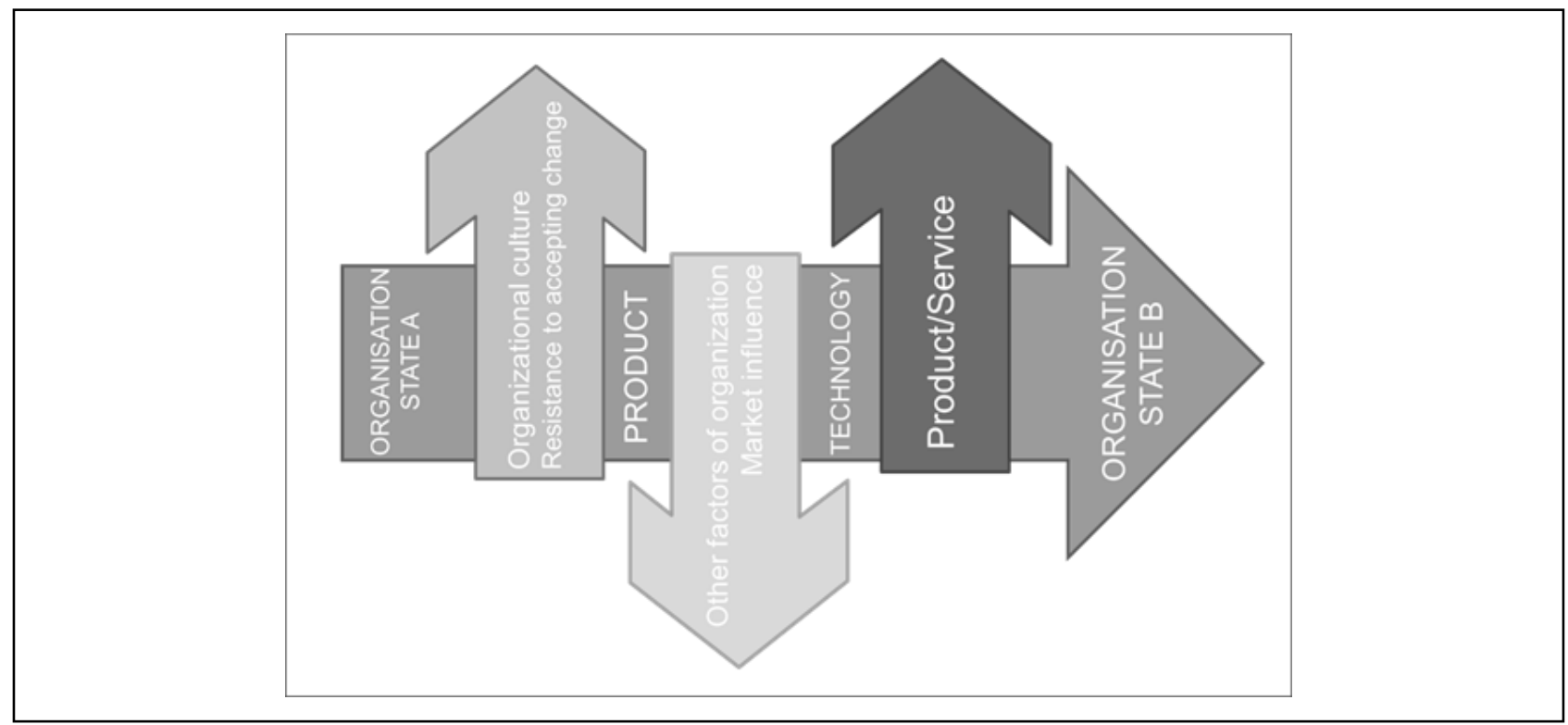

Fig 6. Model of influence on change management process 
A human resource is considered an essential resource of any business system. Every change begins and ends with people. However, every change also undermines the feeling of security that employees develop in the workplace because people usually ignore what they do not want to hear or what is pushing them out of their comfort zone. The works of many authors on the subject of organisational culture clearly suggest that the organisational culture is extremely important for a business system, in fact its character is sublimation of employees' feelings, their behaviour, mutual interaction and, eventually their attitude towards an essential change within the business system.

\section{Conclusion}

New times dictate new circumstances of business which are much more rapid, unpredictable and turbulent. Organisations must therefore be prepared at all times to adapt to changes in the environment in order to be able to implement their own changes. Adequate change management is critical to business success. One of the most significant, if not the most significant, factors of affecting the change management processes is organisational culture. It determines the behaviour of employees through the adopted norms, customs, beliefs, etc. It facilitates stronger connections, communication and sharing of knowledge and experience between the employees, thus making a stronger connection with the organisation. All this entails the basis of creating employees' attitude with a view to implementing necessary change. However, every change generates resistance and if organisations are to make the change, they must adapt their organisational culture, accordingly, making sure that this culture remains a driver and a critical part of the change management process, and not its inhibitor. Such culture becomes a sustainable competitive advantage because it cannot be copied and because it forms a foundation of unique values underlying the success and longevity of the organisation.

Adaptability of organisational structure to the intensity of necessary change under the influence of an organisation's culture in fact presupposes a „living organisation“, a living organism which ensures continued adaptability to people, tasks and business processes. Through the model of a CD organisation, we have offered full flexibility to the challenge of continuous change.

The research of this paper emphasised the importance of the organization, that has to challenge the change process in order to adopt the to ever changing market, and especially, customer demands. The brought importance of the organizational culture as a "glue" for the change management process is shown adequately, but the broader research will be done through specific and targeted company research in our micro region, where such researches were very rare.

\section{References}

Abdul Rashid, Z., Sambasivan, M. and Abdul Rahman, A. (2004), "The influence of organizational culture on attitudes toward organizational change", Leadership \& Organization Development Journal, Vol. 25 No. 2, pp. 161-179 
Aleksic, Ana. (2009). Uloga upravljanja organizacijskim promjenama u izgradnji održive konkurentske sposobnosti poduzeća. The Proceedings of Zagreb Faculty of Economics and Business; Vol.7 No.2.

Alfirevicc N.,Garbin Praniccevicc D.,Talaja A. (2014): Upravljanje organizacijskim promjenama i znanjem, Split,

Amabile, Teresa M (1996), "Creativity and Innovation in Organizations." Harvard Business School Background

Cameron, K. and Freeman, S. (1991) Cultural Congruence, Strength, and Type: Relationships to Effectiveness. Research in Organizational Change and Development, Volume 5

Cook, P. (2002). Best Practice Creativity, Gower Publishing Limited, Hampshire, England

Covic, D. (2004), "Strategy Of Sustainability Of Business Systems Based On Knowledge ", Proceeding of the 3rd International Conference, Business System Management - UPS 2004, Universitiy of Mostar, pp. 071-076

Covic, D. \& Covic, D.(2012): CD-Based Organization of Business Systems, Proceedings of the 23rd International DAAAM Symposium, Volume 23, No.1, ISSN 2304-1382 ISBN 978-3-901509-91-9, CDROM version, Ed. B. Katalinic, Published by DAAAM International, Vienna, Austria, pp, 0457-0458

de Geus, A. (2002) The Living Company, Habits for Survival in a Turbulent Business Environment, Harvard Business School Press, Boston

EESC (2019), EESC Employers Call For An Open, United And Strong EU, "Visits and Publications" Unit, EESC-2019-41-EN

Jung, C.G., (1923), Psychological Types, London: Routledge and Kegan Paul M. Zugaj, J. Sehanovic, M. Cingula (1999), Organizacija, Fakultet organizacije i informatike, Varaždin

Maslow, A. H. (1954). Motivation and personality. New York: Harper and Row

Mazur, Collins, J. C., Porass, J. I. (1994) Built to Last, Successful Habits of Visionary Companies, Harper Business, New York

Mazur, M., Spahic, A.; Grabar, D., Grd, P., Sedlbaurer, G., Sikorska, K., Pallares Beamonte, E.. (2014). Upravljanje znanjem - priručnik za poduzeća. Zagreb: Lifelong Learning Programme.

Mitrof I.I. (1983), Stakeholders of the organizational mind, San Francisco, CA: JosseyBass,

Polasek, P., Simon, M. (2018). Product Innovation Influence on Production Organization, Proceedings of the 29th DAAAM International Symposium, pp.05480552, B. Katalinic (Ed.), Published by DAAAM International, ISBN 978-3-90273420-4, ISSN 1726-9679, Vienna, Austria

Senge, Peter M. (1990). The fifth discipline: the art and practice of the learning organization. New York :Doubleday/Currency,

Stadler, C. (2007) The Four Principles of Enduring Success, Harvard Business Review, Vol. 85, No. $7 / 8$

Zugaj et al. (2004), Organizacijska kultura, TIVA tiskara, Varazdin 